\title{
The Linguistic Situation in Orkesumet, an Urban Area in Simanjiro District of Tanzania
}

\author{
Amani Lusekelo \\ http://dx.doi./org/10.4314/ujah.v20i1.2
}

\begin{abstract}
An investigation of the linguistic landscape in urban Africa is a welcome contribution to make in that multilingualism presents fascinating results. To satisfy this demand, the current paper investigates the patterns of language use in billboards in a small township of Orkesumet in northern Tanzania. Data demonstrates that the state of Kiswahili and English bilingualism is apparently open for religiously, privately and publicly owned institutions such as schools, churches, public offices, and accommodation facilities. Such bilingual billboards do not make use of hybrid language because there were no tokens of Kiswahili-English, Maasai-English and Kiswahili-Maasai recorded in the area. The main mechanism used to attract customers is through the selection of fontcolour and font-size. The large font in black colour is preferred for names of firms, while red colour is opted for items sold and/or services rendered.
\end{abstract}

Keywords: Bilingualism, Billboards, Language Use, Simanjiro, Tanzania

\section{Introduction}

The linguistic situation in Tanzania is arguably claimed to comprise Kiswahili as the main national language used as a lingua franca and official language across the country (Batibo 2000; Petzell 2012). With regard to wider communications in formal settings, English turns the second in command because it manifests in most formal institutions such as schools, high courts, international forum and diplomatic relations (Abdulaziz 1972; Roy-Campbell \& Qorro 1997; Rubagumya 2003; Keya 2016). The ethnic community languages remain confined to informal 
settings in most cases around the homesteads (Batibo 1992; Msanjila 2003; Muzale \& Rugemalira 2008). This paper wants to expose the linguistic situation in urban Tanzania by examining the language use in the billboards found around Orkesumet District Headquarters of Simanjiro in Manyara Region, northern Tanzania.

The Study of linguistic landscape in African cities is growing though much output come from South Africa. For instance, Dowling (2010, 2012), Kotze and du Plessis (2010) and Stround and Mpendukana (2009) examines the linguistic situation in white settlements as opposed to the black suburbs of South Africa. The outcome shows that each area is dominated by a single language. In suburbs, Isixhosa or Isizulu dominates while in white settlements, Afrikaans and English are commonly used. In addition, in South Africa, the billboards obtained in suburbs tend to contain bottom-up language which represents the class of the minority languages, as discussed by Kotze and du Plessis (2010) and Dowling $(2010,2012)$.

In this decade, research on linguistic landscape had been growing in Tanzania. It begins with Bwenge (2009) who presents the Kiswahili and English use in billboards. Peterson (2014) and Chul-joon (2014) examined signboards in Dar es Salaam. Both Bwenge and Chuljoon focus on billboards while Peterson pays much attention to signboards for privately owned firms. Recently, Mdukula (2018) examined linguistic landscape of Muhimbili National Referral Hospital, while and Legère and Rosendal (2019) report on the linguistic landscape being informed by language policy in Africa.

The findings from studies on linguistic landscape demonstrate contradicting results. For instance, while Bwenge $(2009,2012)$ found a two-strand of English and Kiswahili bilingualism in billboards in Dar es Salaam, Peterson (2014) reports of the evidence of multilingualism in shop-signs, with the use of many languages, namely Kiswahili, English, Arabic, Hindi and numerous ethnic community languages. Another difference is reported on the predominance of Kiswahili by Bwenge (2009, 2012) and English by Peterson (2014). Such kinds of different outcomes of researches conducted in the same township call for research 
on other areas in the country as well; hence this research was envisaged to fill the gap.

The studies mentioned above obtained data from the metropole Dar es Salaam. The outcomes of their research does not provide a full picture of the linguistic profile of the country. Lusekelo and Alphonce (2018) examined the language of public space in district capitals in Tanzania. Findings from Arusha and Manyara Regions exhibit the dominance of English. This indicates that Tanzanians affiliate with the language of power in Tanzania, namely the language of ex-colonial master.

Another motivation for the current research emanates from the fascinating findings in urban centres in Sub-Saharan Africa. In Kigali Rwanda, Rosendal (2010) found the adherence to the modern language regulations in main-streets, having predominantly English and French, while the shop-signs in back-streets ignore modern language rules and stick to French and Nyarwanda. In metropolitan cities such as Accra in Ghana and Cape Town in South Africa, it is found that the use of fonttype and font-colour underscores the prominence of some information given in certain languages (Stroud \& Mpendukana 2009; McLaughlin 2012; Quayson 2010), in most cases hybrid language (Higgins 2009). In order to emulate previous studies, the current contribution examines the font-types and font-colour used in billboards in Orkesumet smalltownship in northern Tanzania.

\section{Linguistic Situation in Orkesumet and the Status of Simanjiro Maasai}

Previous studies found different patterns of language use in Tanzania. For instance, in rural areas, Msanjila (2004) found the shift to more Kiswahili than ethnic community languages amongst the inhabitants of the rural area of Ibaba in southern Tanzania. Muzale and Rugemalira (2008) report that both English and Kiswahili dominate the domains which used to be predominantly for ethnic community languages in rural Tanzania. In urban areas, Kiswahili predominates although English remains the language of formal settings, e.g. high court and court of 
appeal (Keya 2016). Batibo (2005) suggests that Tanzanian speech community has the following pattern: English and Kiswahili on top, areally dominant languages, e.g. Ruhaya, Sukuma, Nyakyusa, Maasai and Iraqw are amidst, and minority languages, e.g. Akie, Hadza, Ikizu, Mbugwe, Sandawe, and Segeju at the bottom of the hierarchy (Figure 1). The suggested pattern in Figure 1 is attained in many urban areas in the country. However, the current study of linguistic landscape in a small township of Orkesumet does not obtain the same picture.

The picture of language use portrayed by Batibo (2005) does not reflect each and every situation in Tanzania. For instance, on the basis of a series of studies in Endamagha, Yaeda Chini and Mang'ola wards (Lake Eyasi area) in rural Tanzania, Lusekelo (2015) found the patterns in Figure 2. This pattern is slightly different from the previous one given by Batibo (2005). In this pattern, English is confined in very limited use of formal institutions, mainly in secondary schools where it is used in teaching. Four languages appear to be dominant in Hadzabeland, namely Kiswahili, Datooga, Iraqw and Nyisanzu. These are languages of wider communication around Lake Eyasi area.

Higher status

English and Kiswahili: The prominent languages in formal domains, e.g. schools and courts.

Areally dominant languages: Majority languages such as Sukuma, Maasai and Nyakyusa are prominent languages of wider communication in informal settings.

Minority languages: Least prominent languages which are confined to smaller populations and get used in narrow domains.

Lower status

Figure 1: Language use and predominance in Tanzania. 
Higher status

English: The prominent language in formal domain of secondary education.

Kiswahili: The prominent language in formal domains such as church and primary schools and informal domains like sports.

Areally dominant languages: Majority languages, e.g. Datooga, Iraqw and Isanzu are prominent languages of wider communication in informal settings.

Minority language of Hadzabe: Least prominent languages which are confined to the foragers.

Lower status

Figure 2: Language use and predominance around Lake Eyasi in Tanzania.

In both patterns (Figure 1 and 2), the alignment of Kiswahili as the languages of wider communication remains central throughout the country (Blommaert 1992). Likewise, the predominance of English, which is the language of upward mobility (Blommaert 2013), cannot be overlooked. The current research was conducted within Simanjiro District. The research site is Orkesumet Township (see Map 1) (URT 2015). Data was gathered within the district headquarters at Orkesumet.

Orkesumet is a typical Maasai township in Tanzania. Most of the Maasai people lived in the Maasai District. According to Hodgson (2005: 112-113, the Maasai District existed in the late 1950s but it was split into Kiteto District and Monduli District in 1974 and Ngorongoro District in 1979. According to URT (2013: 26, 190), the typical Maasai districts of Tanzania include Kiteto, Longido, Monduli, Ngorongoro, and Simanjiro. 


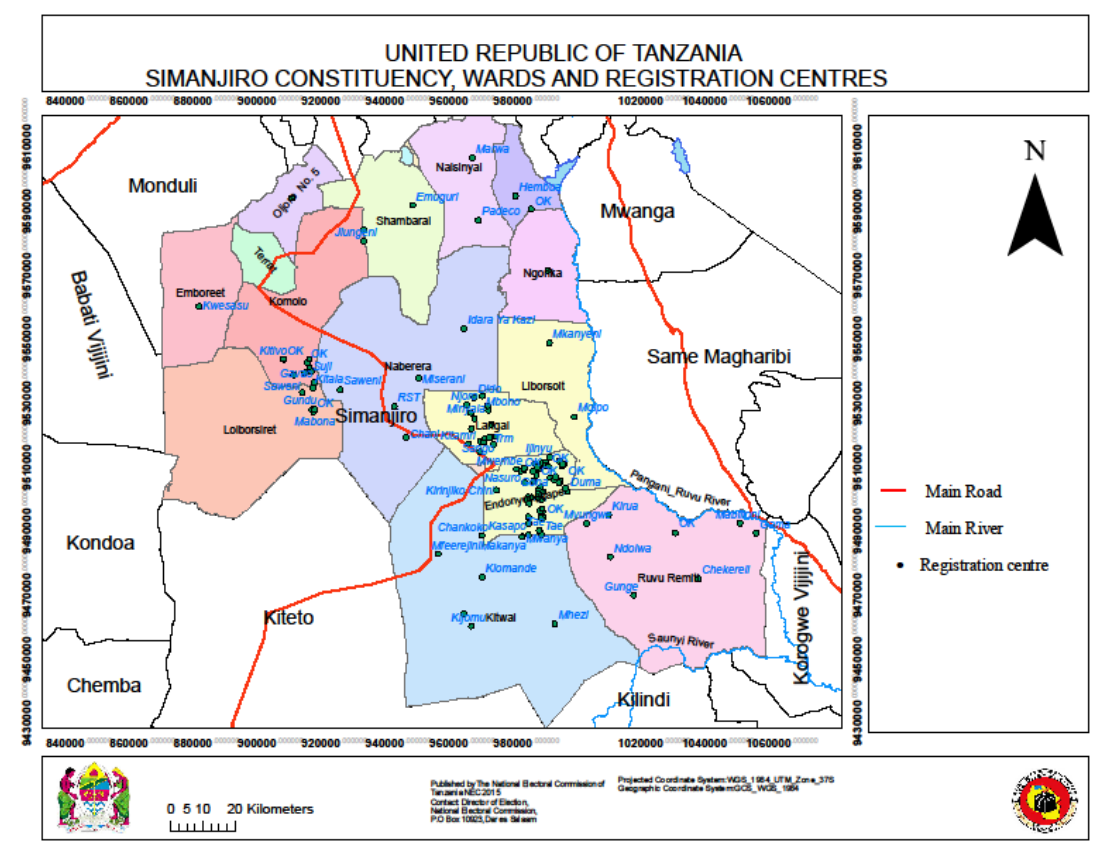

Map 1: Administrative Wards in Simanjiro District (URT 2015)

Historically, Orkesumet was predominantly a small Maasai village between 1957 and 1977 within the Maasai District of Tanzania (Jacobs 1978), which is now divided into several administrative districts, namely Arusha District Council, Kiteto, Longido, Monduli, Ngorongoro and Simanjiro (Yanda \& William 2010; URT 2013). In 1988 census, Orkesumet was not assumed as an independent district headquarters rather it was treated as part of the Arumeru and Kiteto Districts (URT 1988, 1998). Again, in the 2002 census, available information shows that Orkesumet township was not even a full-flagged administrative ward in Simanjiro District, rather it was part of the large ward with mixed (urban and rural) settlements (URT 2002; LOT 2009). It means that Orkesumet 
remained a Maasai village where Maasai language remained the dominant vehicular of communication.

Transformation programs were instituted in the Maasai villages. According to Hodgson (2005: 112-113), the Maasai pastoralists should no longer be characterized as conservative and predominant adherents of the traditions, customs, rites and beliefs perpetuated through informal education. This is because transformation happened in their villages. By 1990s, their lives in Maasai districts had been transformed by the numerous. The penetration of Kiswahili and English should therefore be considered together with the transformation of this community.

The Maasailand in Simajiro District, as well as in other parts of Maasai Steppe in Tanzania, experienced transformations through villagization and resettlement programmes organized by the Government of Tanzania (Ndagala 1982; Århem 1985), construction of physical infrastructures such as roads, health centres and schools (Yanda \& William 2010), and promotion of tourism and mining sectors mainly around Mererani township (Sachedina \& Trench 2009). Given the changes over the last fifty years, Orkesumet experienced massive transformations, similar to other Maasai villages. In addition, the Maasai culture is in the edge of massive change due to encroachment of the Maasai district by the non-pastoral societies who immigrate to the Maasai villages in the district (Omri-Pack 1998; Yanda \& William 2010). Such changes are not fully conceived by Jacobs (1978) who perceives that the Maasai culture remained intact irrespective of the massive investments in education, villagization and modernisation.

It is reported that the conditions of the landmass in Simanjiro appear to have deteriorated. Omri-Pack (1998:95) comments that, "in some parts of the Maasailand the loss of pastoral land has led to land degradation, caused by various factors, such as overgrazing and unsuitable agriculture in marginal lands." The land degradation is associated with stress in pastoralist economy. Yanda and William (2010:154) highlight that "the stress stemming from prolonged recurrence of droughts and anthropogenic activities such as expansion of 
smallholder crop cultivation, creation of protected areas such as game reserves and opening up of large - scale farms."

According to the national census (URT 2013:195), Orkesumet Township in Simanjiro District was composed of two administrative wards whose demographic information is provided below. In the 2015 elections, Orkesumet Township had been split further (URT 2015). Now it is composed of the three administrative wards, namely Endonyongijape, Langai and Orkesumet.

\begin{tabular}{|l|l|l|l|l|l|}
\hline S/N & Ward & $\begin{array}{l}\text { Total } \\
\text { Population }\end{array}$ & Males & Females & $\begin{array}{l}\text { Household } \\
\text { Size }\end{array}$ \\
\hline 1. & Orkesumet & 5,325 & 2,601 & 2,724 & 4.1 \\
\hline 2. & Endonyongijape & 10,153 & 5,061 & 5,092 & 5.5 \\
\hline & TOTAL & $\mathbf{1 5 , 4 7 8}$ & $\mathbf{7 , 6 6 2}$ & $\mathbf{7 , 8 1 6}$ & $\mathbf{4 . 8}$ \\
\hline
\end{tabular}

With regard to the dominant languages in the area, the Atlasi ya lugha za Tanzania (LOT 2009:49) provide the following dispersal of languages in Simanjiro District. The Maasai is the main language of communication in the whole district. Exception to this linguistic situation is found in northern parts of the district at the mining centre of Mererani ward where Kiswahili is the dominant language. Sachedina and Trench (2009) noticed the immigration of many non-Maasai people in the area. Another exception is found in eastern parts. Simanjiro District shares a boundary with Mwanga, Same and Korogwe Districts which have predominantly the Chasu (Kipare) speakers. As a result, Chasu (Kipare) turns the dominant language of communication in Ngorika and RuvuRemiti wards (LOT 2009). However, Maasai is the second dominant language in these wards. It means that Maasai is highly used even in the non-Maasai villages in the district.

As regards the secondary language of wider communication in the district, the Atlasi ya lugha za Tanzania (LOT 2009:50) gives this picture: Orkesumet ward is dominated by Kiswahili speakers, Shambarai ward in the north and Loiboroit ward in the east have Chasu (Kipare) as the second large language, and Iraqw is spoken in the western parts. The second largest language after Maasai turns to be Kiswahili, the national 
language which is spoken mainly in Orkesumet ward. On the basis of LOT (2009) statistics, Simanjiro District provides the following portrait of language use in villages.

Higher status

\begin{tabular}{l} 
Kiswahili: The prominent language in mixed-ward of \\
Orkesumet and it is used in formal domains, e.g. schools and \\
government offices. \\
\hline $\begin{array}{l}\text { Areally dominant language: Maasai is the prominent } \\
\text { language of wider communication in informal settings. }\end{array}$ \\
$\begin{array}{l}\text { Chasu (Kipare) and Iraqw: Least prominent languages } \\
\text { which are confined to smaller populations in eastern and } \\
\text { western parts. }\end{array}$
\end{tabular}

Lower status

Figure 3: Language predominance in Simanjiro District.

\section{The Language Usage in the Billboards}

The language of the public domain differs from one organisation to another. There are billboards for public (government) institutions and signposts for privately owned businesses. Given this background, two kinds of signage is developed: the top-down signage, which constitutes the public institutions, and bottom-up signage, that deals with privately owned businesses. The notion government signage and private signage was coined by Thom Huebner to describe the different patterns of language use in official billboards and inscriptions on public buildings (government signs) and signboards and inscriptions on privately owned shops (private signs) (Huebner 2006). In the current literature, the label top-down and bottom-up have been formalized for the purpose of representing public signs and private signs respectively (Juffermans 2013; Blommaert \& Maly 2014).

The study of the signposts and billboards in the world, some tools are used to gather data. Ben-Rafael et al. (2006) and Lanza and Woldermariam (2009) capture the research sites as follows: 
a) names of buildings (both private and public)

b) road signs and directions (town streets) provided by authorities

c) the written public announcements in public offices and roadsides

d) the names of streets, town centres and town parks

e) the signs available along the highway signs

f) commercial shop signs provided in market centres and town streets

g) the contents of the advertisement billboards

h) the fonts and colours of the names in public institutions

Each of the parameters offered above provide results that summarize the language use $n$ public domains. A number of studies on linguistic landscape in African towns used comparative approach to the sociolinguistics (see Peck \& Banda 2009; Stroud \& Mpendukana 2009; Rosendal 2010; Juffermans 2013; Lanza \& Woldermariam 2014, among others).

Based on parameters mentioned above, we find some patterns. Lanza and Woldermariam (2014: 395) report of multilingualism in Ethiopia in which 40 percent of the total population speak Oromo and 32 percent of the population speak Amharic and Tigrinya. Ethiopia has its own script called Fidel and native languages are written in it. Until 1991 when Amharic dominated the language of literacy in primary education, many regional languages were introduced in mother tongue education in Ethiopia after the launching of the policy of ethnic federation (Ibid: 396). This means that multilingualism is an official phenomenon in this African country.

English, with a Roman script, is recognized as the widely spoken international language of Ethiopia. Globalization has influenced migration and commercialization in many areas in the country. A report by Lanza and Woldermariam (2014: 397) indicate that Ethiopia is moving into urbanization and increased middle class which demand goods and services. The modernization of Ethiopia attracts commercialization and globalization and spread of English.

Addis Ababa revealed international brand trademarks being disembedded from their original text. In this regard, English is used for 
scale in shop signs in local environments (Lanza \& Woldermariam 2014: 399). This phenomenon is also reported in South African local shops which use brand names in English even though the majority of the people in the neighbourhood do not command the language.

Lanza and Woldermariam (2014) recognize the presence of Fidel script in international firms such as hotels. This entails that Ethiopians have not divorced from their national identity by their system of writing. The paper articulates that although Addis Ababa witnesses commercialization, globalization, and the growth of English in Roman script, the native language is also maintained.

Another unique picture of African multilingualism is observed from South African city of Cape Town. The publications by Peck and Banda (2009) and Stroud and Mpendukana (2009) employ a semiotic approach to the analysis of the signage in Cape Town, South Africa. The former used data from Observatory Street occupied mainly by white immigrant populations (Lithuanians and Jews) and dominated by English language rather than Afrikaans. The latter used photographs from Khayelitsha suburb of Cape Town which is predominantly isiXhosa speaking township though Afrikaans and English are also used languages in the area.

It is interesting to notice that both publications recognized the dominancy of English in public boards, presence of one national language (Afrikaans and isiXhosa) in public bards and shop signs, and utilization of Africanized (hybrid) language in the shop signs. Stroud and Mpendukana (2009) found that the billboards make use of hybrid tantalizing wording, English compounds, isiXhosa phrases, and nonstandard English spellings. Hybridity is also reported by Peck and Banda (2009) who found the use of isiXhosa, Afrikaans and English. This kind of information is paramount in understanding linguistic landscape in multilingual African cities whose demographics split per ethnic background and nationalities.

The literature above shows that both national languages and international languages dominate the billboards. However, the regional languages also manifest in the signposts. Now much attention will be 
paid to the language of billboards as described by the information gathered in Orkesumet.

\section{Patterns of Language Use on the Selected Billboards}

The billboards in Orkesumet capital of Simanjiro District split thrice. The first strand involves the billboards for some of the public organizations, parastatals and associations which are typically monolingual in Kiswahili. These are the top-down signs in Tanzania. The category is represented by the cases of TANESCO and MAHAKAMA billboards (Figure 1).
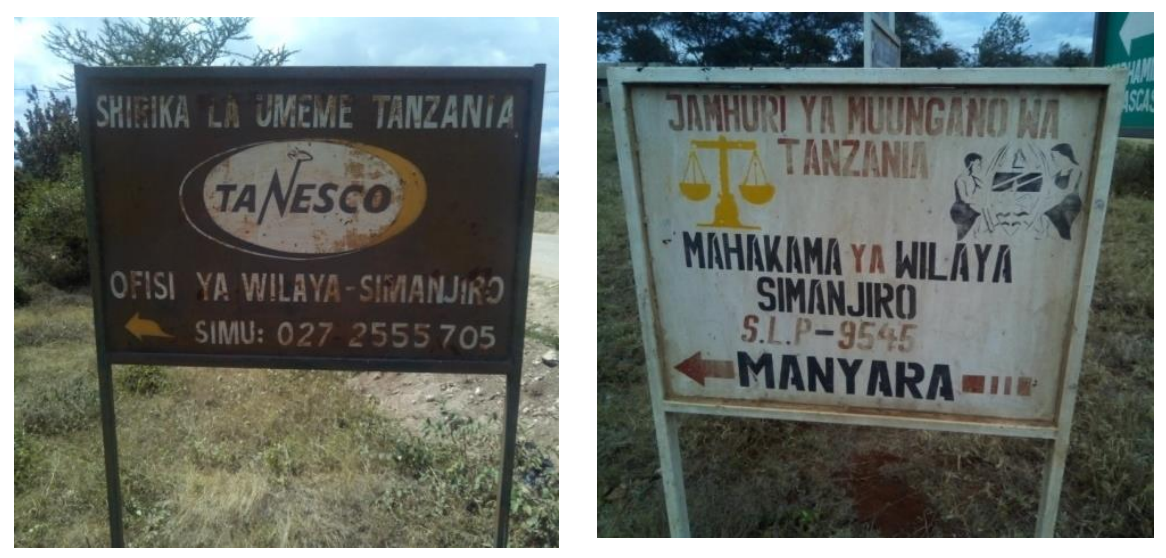

Figure 1: Kiswahili-only billboards for public institutions.

The first image contains these lines in Kiswahili, as given in (1). The second image contains Kiswahili words in (2). All the entries in both images contain Kiswahili-only words.

(1) SHIRIKA LA UMEME TANZANIA 'Tanzania Electricity Supply Company: shorthand TANESCO', OFISI YA WILAYA SIMAJIRO 'District Office - Simanjiro' and SIMU 'Phone': 027 2555705. 
(2) JAMHURI YA MUUNGANO WA TANZANIA 'The United Republic of Tanzania', MAHAKAMA YA WILAYA SIMANJIRO 'District Court Simanjiro' and S.L.P (shorthand for Sanduku La Posta) 'Post Office Box'.

Likewise, the billboards for religious institutions manifest in Kiswahili-only. This is represented by the church services posters, church organisations and church-owned health centres and hospitals. The Lutheran Church of Tanzania is categorically representing the monolingual pattern, as shown in Figure 2.
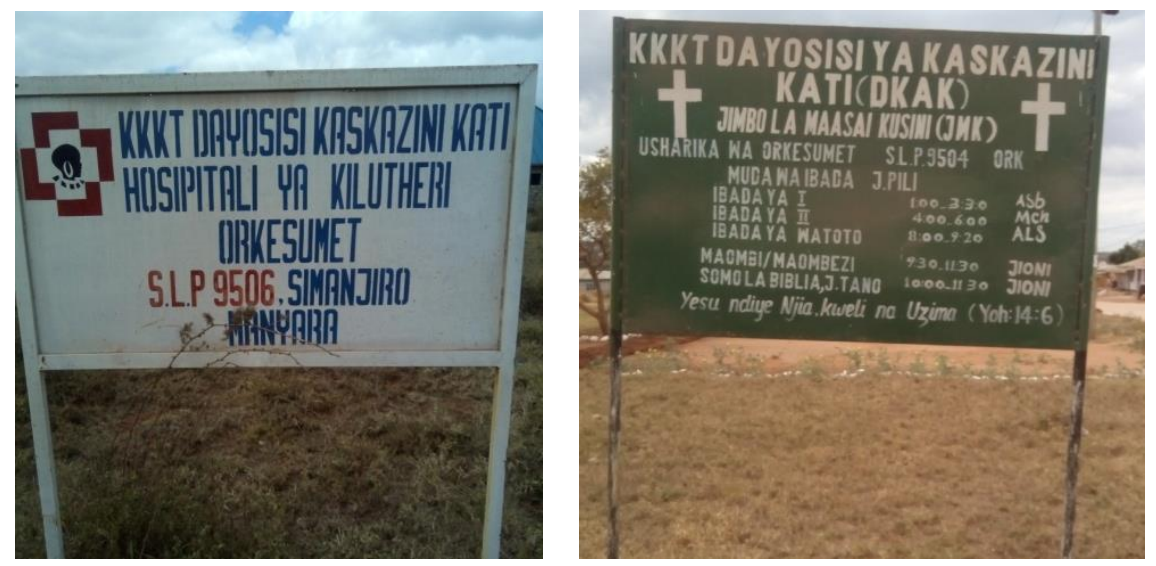

Figure 2: Monolingual Kiswahili billboards for church institutions

The first image in Figure 2 contains Kiswahili lines given in (3), while the second image has its Kiswahili words translated in (4). These church-oriented billboards are given in complete Kiswahili.

(3) KKKT DAYOSISI KASKAZINI KATI 'Lutheran Church North Central Dioceses', HOSPITALI YA KILUTERI ORKESUMET 'Lutheran Hospital Orkesumet', S.L.P (Post Office Box).

(4) KKKT DAYOSISI KASKAZINI KATI (shorthand: DKAK) 'Lutheran Church North Central Dioceses', JIMBO LA MAASAI 
KUSINI (shorthand: JMK) 'The Maasai South Province', USHIRIKA WA ORKESUMET 'Orkesumet Parish', MUDA WA IBADA 'Service Hours', IBADA YA I 'Mass I', IBADA YA II 'Mass II' and IBADA YA WATOTO 'Sunday School', MAOMBI/MAOMBEZI 'Fellowship', SOMO LA BIBLIA 'Bible Study' and Yesu Ndie Njia ya Kweli na Uzima 'I am the way and the truth, No one comes to the Father except through me'.

Some billboards in Orkesumet represent the second strand which comprises English-only. These are primarily billboards for public secondary schools and health services, as shown in Figure 3. Every word in the billboards is English. Even abbreviations are in English, e.g. KM 'Kilometer' and P.O. 'Post Office'.
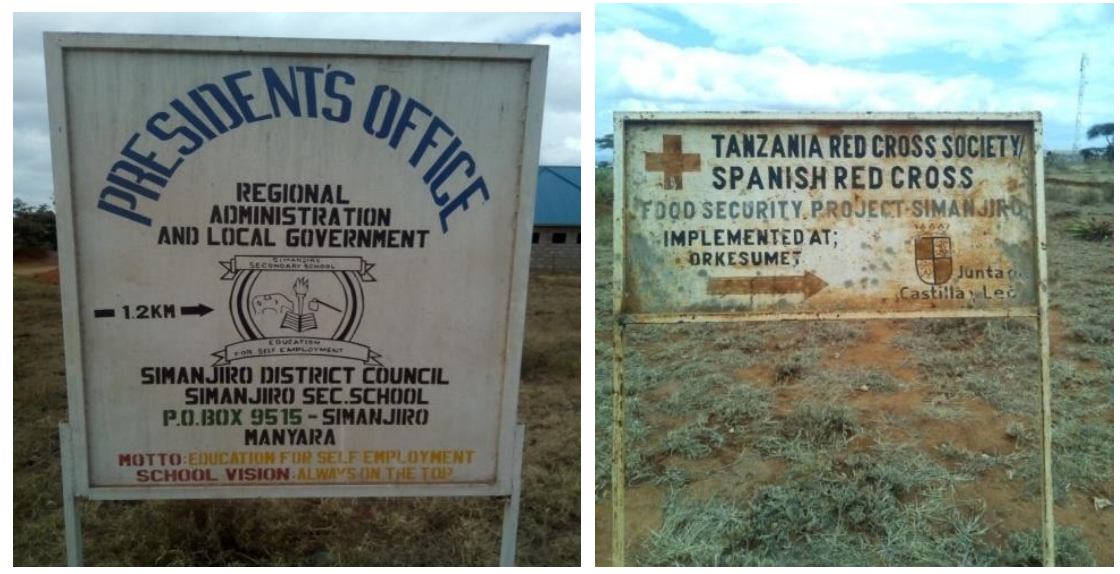

Figure 3: English-only billboards for public institutions

A good deal of privately owned firms prefers English-only billboards. This is apparently open for the billboards of lodges and rest houses, as exemplified in Figure 4. 

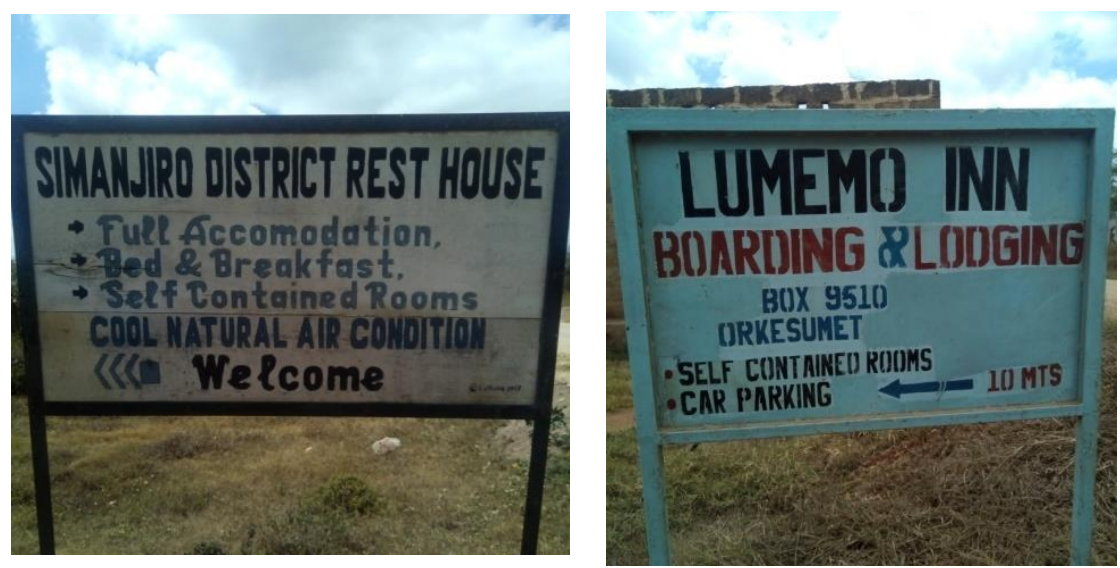

Figure 4: English-only billboards for private firms

The billboards which either use complete Kiswahili or Englishonly adhere to the language policy of Tanzania. The policy statements prescribe that English and Kiswahili are the languages to be used in public domains such as mass media, political campaigns, village meetings, religious services etc. For instance, the Information and Broadcasting Policy stipulates that "the languages of mass media in the country are Kiswahili and English" (URT 2003, 9). Therefore, most of the top-down billboards adhere to this regulation.

The church-oriented billboards also adhere to the regulations stipulated in the Information and Broadcasting Policy (URT 2003). Its signboards have been shown to be prescribed in complete Kiswahili. Likewise, the privately owned forms adhere to the policy statements. Chul-joon (2014) argues that the agency of language of public domain has remained primarily the government which provides stipulations on language of public space.

Lusekelo and Alphonce (2018) argue that in district headquarters, most privately owned firms have used English rather than Kiswahili. The reason is that the owners ascribe English with modernity and development. They choose the language of international communication in prescribing their businesses. 
Another subject matter presented in the data above concerns hybridity of the language of public space. Higgins (2009) discusses the mechanisms employed by Tanzanians to represent the hybridity of English as being blended into Kiswahili and vice versa. The data above provides some more data for discussion.

In Tanzania, dominant words are used to expression certain information, e.g. contacts. Findings from Simanjiro District are varied. In provision of contacts, the English alternative is not highly preferred. Firstly, for the indication of mail contacts, almost 33.33 percent of all billboards make use of the expression P.O. BOX and/or BOX 'Post Office Box'. The Kiswahili means of indication postal address is through S.L.P 'shorthand for Sanduku La Posta' which comprises about 25 percent. This difference is not quite big. With regard to telephone contacts, the English word TEL 'telephone' constitutes only 16.66 percent while the Kiswahili word SIMU 'telephone' is less by half as it comprises 8.33 percent. The contacts via FAX, written in English, constitute only 16.66 percent. This kind of differentiation, however, does not support the findings by Peterson (2014) who identified language choice on the basis of some functions. Kiswahili words, according to her, are primarily used to express different kinds of services. For example, in expression of contacts, almost 95 percent of English words used in firms tend to mention contact, telephone, mobile, call, cell and hotline while only 5 percent of Kiswahili words simu 'telephone' or mawasiliano 'contacts' are used (Peterson 2014). In her data, the English words, therefore, surpass by far the Kiswahili words.

It is obvious now that hybridity of language use in the consumerrelated atmosphere is a common place phenomenon in Africa, as postulated by Higgins (2009) for Tanzania and Stroud and Mpendukana (2009) for South Africa. It is obvious that in Tanzania, hybridity is a result of the merge between Kiswahili and English, the two official languages. In South Africa, hybridity is between Afrikaans, English and Isixhos, in case of Cape Town (Stroud and Mpendukana 2009).

Higgins (2009) contends that hybrid language in Africa emanates from the contact between African communities with the colonial and 
post-colonial administrators and traders. In this contact situation, an exchange of linguistic materials happened for the last 200 years, particularly after the domination of English and Kiswahili in the education and official sector since the Germany and British rule in between 1880 and 2000 (Myers-Scotton 2006; Higgins 2009).

Findings indicate that hybridity is not relevant in Orkesumet. Higgins (2009) found that hybrid language use is a phenomenon is not limited to East Africa rather it is attested across the globe. Many people worldwide exploit English to produce different types of hybrid languages which result from mixing of various languages. Another scholar, Bwenge (2009, 2012), found English and Swahili hybrid language in billboards of multinational companies such as Coca-Cola and Voda-Phone. Findings from Orkesumet in Simanjiro do not support this phenomenon. The billboards in the area maintain bilingualism of Kiswahili and English. Perhaps this is a testimony that hybrid language is indeed used in metropolitan cities in Africa, as is the case of Dar es Salaam in Tanzania (Bwenge 2009; Higgins 2009), Cape Town in South Africa (Stroud \& Mpendukana 2009) and Accra in Ghana (Quayson 2010).

Another point to underscore here involves the use of ethnic community language in hybridity. Higgins (2009) argues that hybrid language tend to merge linguistic materials from not only colonial languages but also ethnic community languages. In Tanzania, areally dominant languages such as Kichagga and Kihaya are predominantly used in formal settings when people of similar ethnic background converse (Higgins 2009). However, the hybrid language use could not make use of such linguistic materials from ethnic community languages. Findings from Orkesumet indicated that the tokens of English and Kiswahili dominated. I did not find the hybridity between Maasai and Kiswahili, nor Maasai and English. I am convinced that hybridity require major companies which would want to localize its multinational products into local Englishes. The case of Coca-Cola and Voda-Phone, which Bwenge (2009) and Higgins (2009) mention, is really a good one to consider here. 
The third strand contains bilingual billboards. Many billboards for both public institutions and offices and private firms are composed in English and Kiswahili. These billboards split twice. Firstly, there are billboards in which both Kiswahili and English are given equal weight. Perhaps the example case in Figure 5 will help to illustrate this point. The billboard shows the use of Kiswahili segments HALMASHAURI YA WILAYA and thereafter its English equivalent in brackets (Simanjiro District Council). Likewise, the word MAKAO MAKUU has its translation in brackets (Headquarters). It follows, therefore, in such billboards, both languages manifest at equal interval with complete sense. In fact, for these billboards, the texts for English and Kiswahili appear in complete and independent segments.

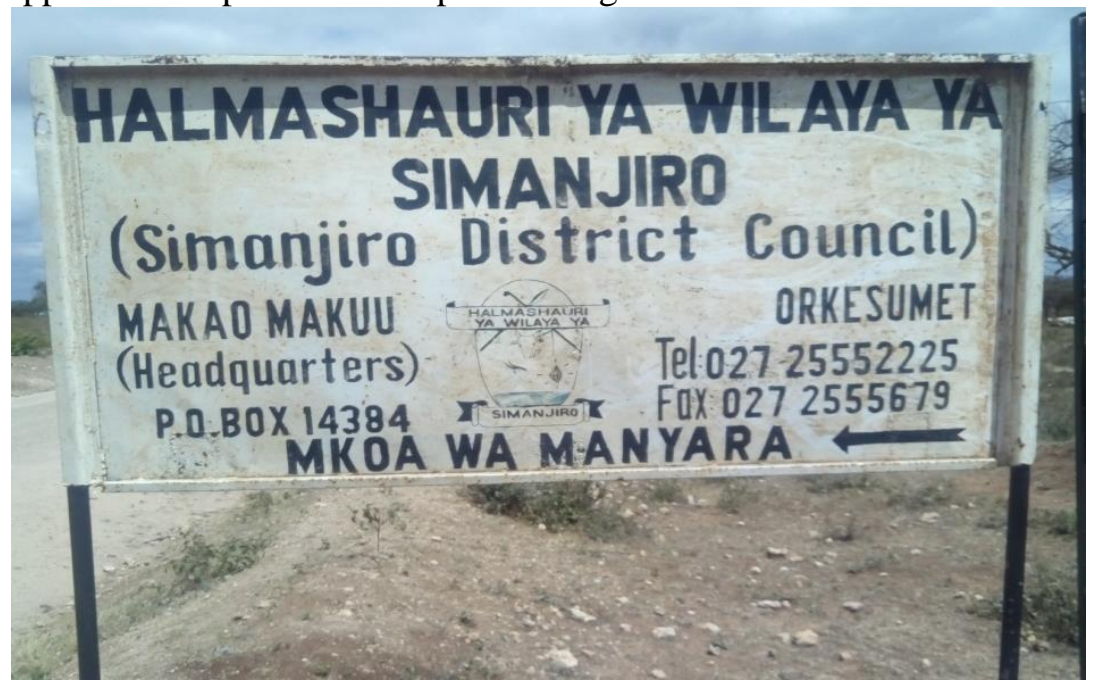

Figure 5: Kiswahili-English billboard in Simanjiro.

The perfect interval obtained in Figure 5 above does not manifest in most Kiswahili and English billboards; rather some of them contain independent segments but not typically at regular interval. For example, Figure 6 provides English-Kiswahili billboards for public institutions and offices. Figure 7 gives exemplary cases for the billboards composed for 
the church-oriented posters. Such data demonstrate that though both languages are used, the choice of one language appear to override the other. Figure 6 demonstrates that English supersedes Kiswahili while Figure 7 shows that Kiswahili overrides English.
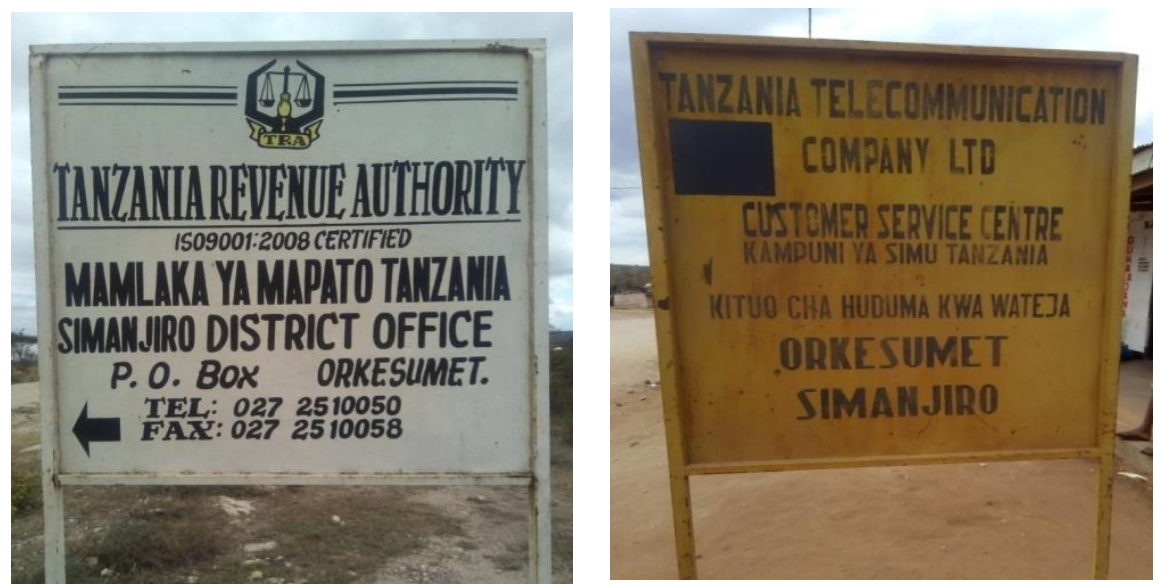

Figure 6: The bilingual EnglishKiswahili billboards for public offices and institutions. 

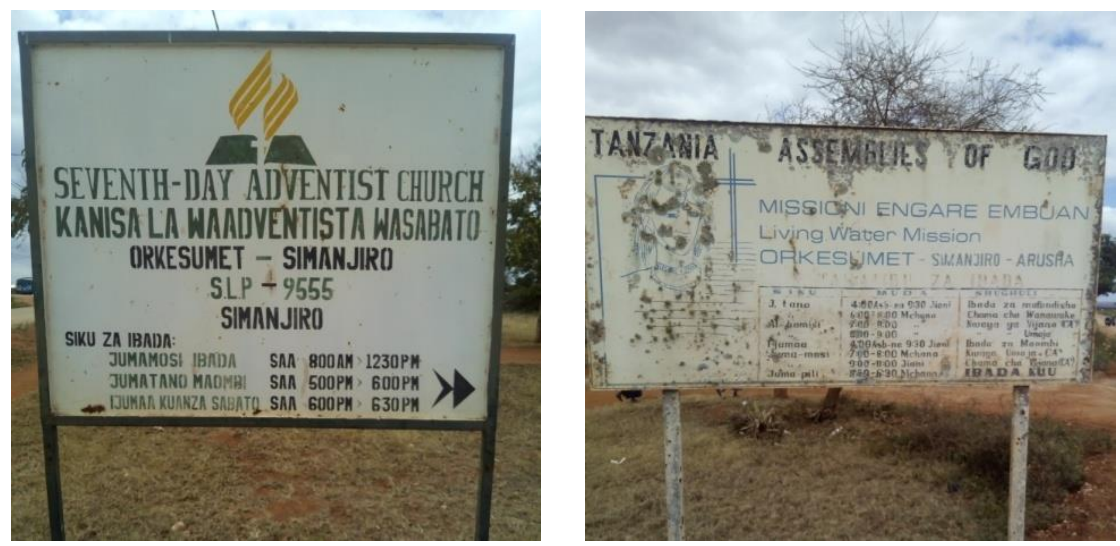

Figure 7: The bilingual English-Kiswahili billboards for the churchoriented placards

Since the contents of Figure 6 could easily be followed, I translate the contents of Figure 7 which is slightly different. In this case, the amount of English words have not been given equal weight to that of Kiswahili. The Kiswahili words in the first image appear in (5) and those for the second image are in (6):

(5) SIKU ZA IBADA JUMAMOSI IBADA SAA JUMATANO IBADA SAA IJUMAA KUANZA SABATO
'Service or Mass Days'

'Saturday Mass at'

'Wednesday Mass at'

'Friday commencement of Sabbath'

(6) SIKU 'day'

MUDA 'time'

J. tano 'shorthand for Wednesday'

Alhamisi 'Thursday'

Juma-Mosi 'Saturday'

Juma-Pili 'Sunday'

SHUGHULI 'activity'

Ibada za Mafundisho 'Bible School'

Chama Cha Wanawake 'Women's Association'

Ibada za Maombo 'Fellowships' 


\section{Kwaya 'Choir'}

Backhaus (2007) and Rosendal (2010) highlight correctly that the amount of words used in a single billboard counts a lot in the analysis of the importance of one language over the other in bilingual billboards. A quick glance at the data (Figure 6) indicates that both Kiswahili and English have been given equal weight though each occurs at independent interval. At this juncture, it will be plausible to argue that KiswahiliEnglish billboards in Simanjiro District Headquarters consider equal weight of both languages.

The Information and Broadcasting Policy of Tanzania stipulates that both languages can be used in the public domain. Therefore, codeswitching between Kiswahili and English is allowed. In line with Chuljoon (2014), the use of code-switched English and Kiswahili respects the government instructions. Therefore, the government remains the main agent for the formation of language of public domain in Simanjiro, Tanzania.

Secondly, a number of bilingual billboards are skewed in that one language is given more weight than the other. In these billboards, the dominance of English is obvious. For instance, MBOGO STATIONERY has provided only a dependent segment of the Kiswahili expression CARD ZA MWALIKO 'invitation cards'. Therefore, the prominence of English cannot be underestimated here. 


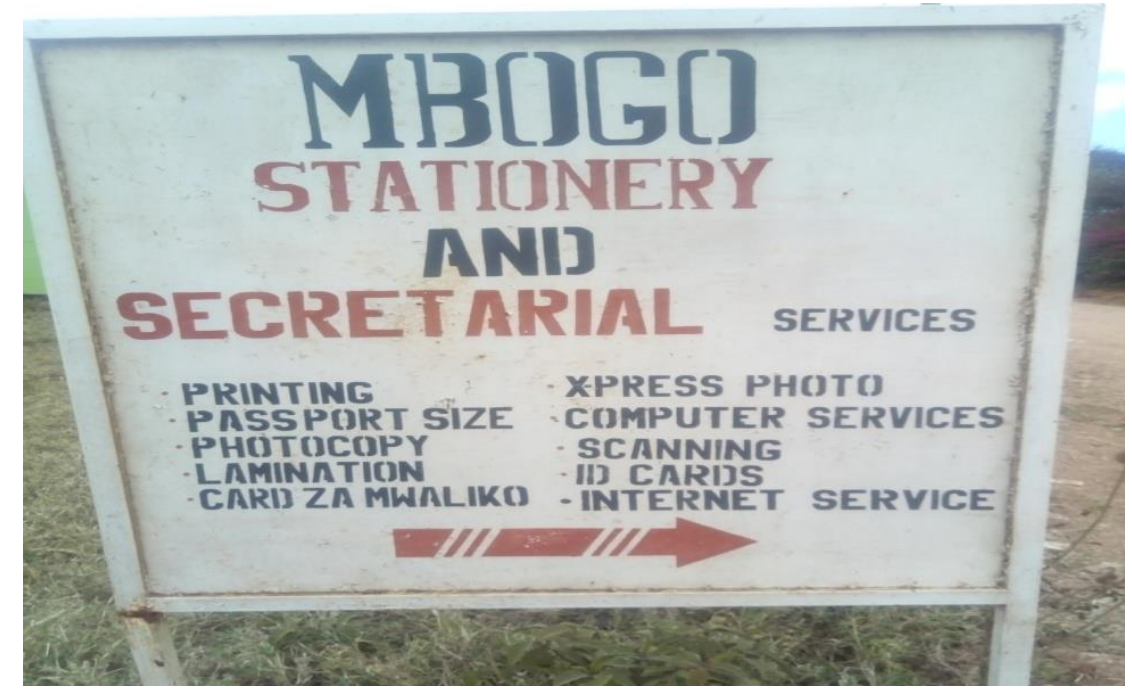

Figure 8: The skewed English-Kiswahili billboard.

More issues unfold from the foregoing presentation. First, the discussion about the state of multilingualism in billboards in Orkesumet has to be compared to the billboards available in Dar es Salaam. Second, investigation of the use of hybrid language in Orkesumet has to be compared to the metropolitan cities of Africa, namely Dar es Salaam, Accra and Cape Town.

On the first account, an in-depth investigation of bilingualism in billboards requires examination of font-size and font-colour. In fact, a given colour provides some added information to the text in the billboards. Backhaus (2007) found that the use of red colour on background symbolizes meaning and yellow colour on vegetables entail vitamins in food. Billboards in Orkesumet have black, blue, white and red colours. The difference lies on the use of high fonts of the black colour for the names such as TANZANIA DISTRICT REST HOUSE, TANZANIA REVENUE AUTHORITY, HALMASHAURI YA WILAYA YA SIMANJIRO 'Simanjiro District Council' etc. 
The significance of font-size and font-colour is examined using data in Figure 9. The focus is on the name of the institution and/or firm which is represented in the billboards. The ethnic names such as LUMENO IN and MBOGO are words from ethnic community languages. These names are given prominence by assigning them with an exposed font. Backhaus (2007) and Rosendal (2010) suggest that this is one way of foregrounding a language. In this case, the ethnic community languages have been foregrounded using the names.
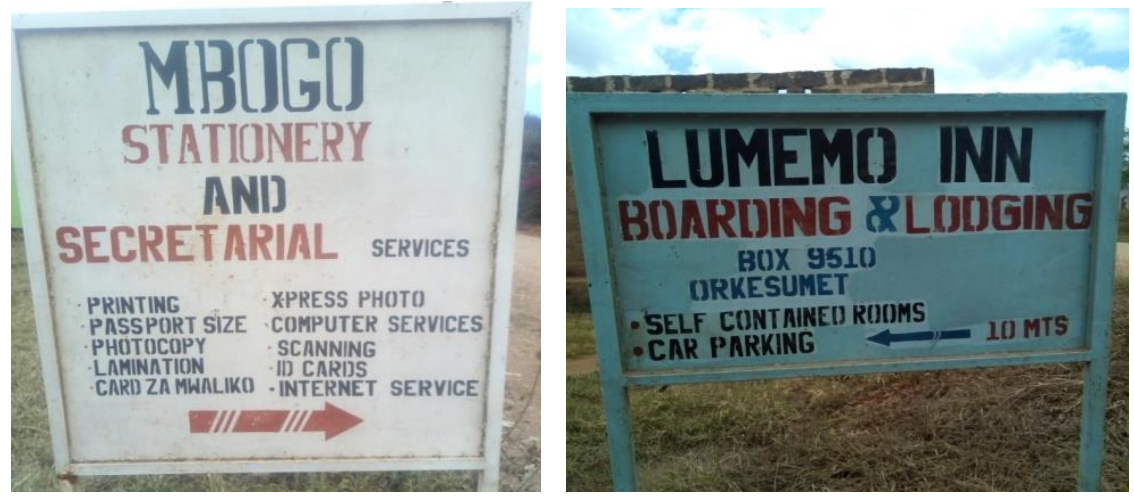

Figure 9: Font-size and colour in billboards in Orkesumet Township

The information about the services tends to be provided in special fonts. For example, the words STATIONERY and SECRETARIAL as well as BOARDING and LODGING appear in red colour (Figure 9). It is important to notice that the choice of the font size is essential in indication of the items sold and/or services provided. Scholars in linguistic landscape (cf. Backhaus 2007; Rosendaal 2010; McLaughlin 2012, among others) insist that the choice of a certain font provides extra information to the consumers in the world of commercials.

Language contact is another phenomenon attested in the data. The situation in the small township of Orkesumet is related to the 
expansion of the tourism sector in Arusha region and tanzanite mining sector at Mererani ward. The establishment of tourists' attraction centres such as Lake Manyara National Park, Ngorongoro Conservation Area, Tarangire National Park etc. attract many foreign and local immigrants (cf. Homewood 2009; Sachedina and Trench 2009; Hodgson 2011). Consequently, the commutation of people between Arusha and Orkesumet and Mererani and Orkesumet is really robust (Figure 10). This has implications to the language contact in Orkesumet because Kiswahili becomes the major vehicular of communication the nationals. In addition, English becomes the main language of communication with foreigners. In Tanzania, as Higgins (2009) argues correctly, this situation includes rapid urbanization and a bringing together of different ethnic communities and cultures with a concomitant exposure to different ways of being. Thus, inhabitants of Orkesumet copy from the different groups.
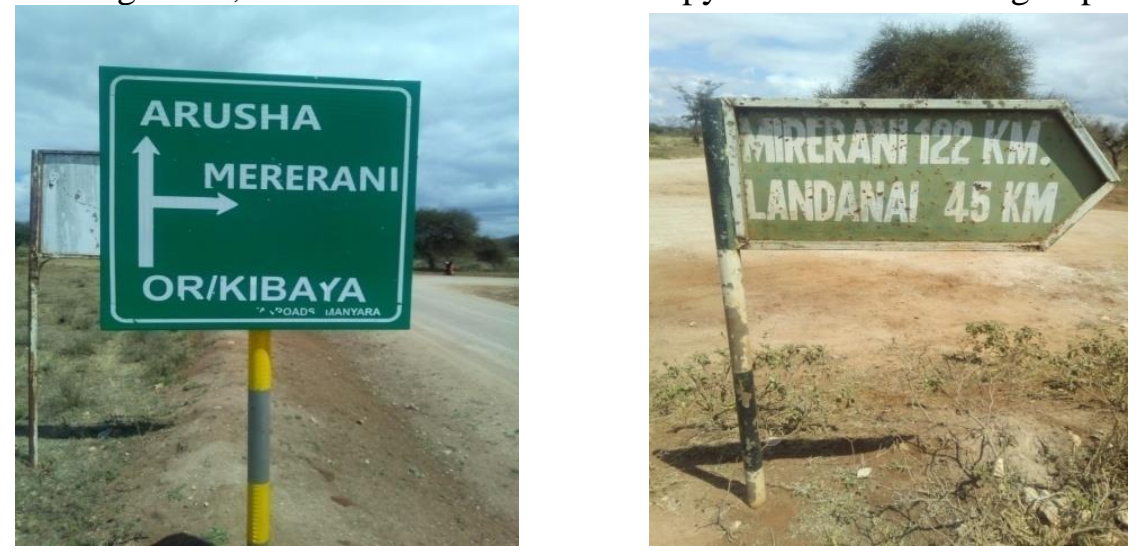

Figure 10: Road signs in Orkesumet Township

The English abbreviation KM 'Kilometer' is used in Figure 10. This is commonly used in many of the signposts analysed in this article. The abbreviation OR is localized for Orkesumet township. 


\section{Conclusion}

The paper investigated the patterns of language use on billboards in Orkesumet, a small township in northern Tanzania. The data from this research site reflects partly the findings obtained in other district headquarters in the country (Lusekelo \& Alphonce 2018). The findings showed that the linguistic landscape in urban areas of Tanzania utilizes Kiswahili and English, as prescribed by the Information and Broadcasting Policy (URT 2003). Both the top-down and bottom-up signage chooses one of the available options: English-only, completely Kiswahili or English-and-Kiswahili.

The picture obtained in Orkesumet is not unique to this township. In Dar es Salaam, Bwenge (2009) and Peterson (2014) found that Kiswahili and English predominate as the language of the public space. Both Kiswahili and English bilingualism is apparently open for religiously, privately and publicly owned institutions such as schools, churches, public offices and lodges. The manifestation of the ethnic community languages is limited to personal names such as MBOGO 'buffalo'. Therefore, it is only Kiswahili and English which obtain dominance in billboards. This is not uncommon because regulations in Tanzania permit only two languages, namely English and Kiswahili as the languages of formal communication. Msanjila (2003) argues that if this kind of regulation remains at work in the country, the status of ethnic community languages such as Maasai will continue to be threatened. This claim is confirmed by the findings in Simanjiro District in which Maasai is the language of wider communication but does not manifest in billboards rather English and Kiswahili are highly used.

The small township of Orkesumet witnessed expansion of the commutation of people between Arusha and Orkesumet and Mererani and Orkesumet. The commutation brings language contact whereby Kiswahili becomes the major medium of communication the nationals and English becomes the main language of communication with foreigners. The use of hybrid language in consumer communities is expected in such a situation (Higgins 2009). However, findings from 
Orkesumet in Simanjiro do not support the use of hybrid language in billboards. The billboards in the area maintain bilingualism of Kiswahili and English. The hybridity between Maasai and Kiswahili or Maasai and English is not available in the data. This is a good testimony only the metropolitan cities in Africa, e.g. Dar es Salaam, Cape Town and Accra can attract hybridity.

Amani Lusekelo

Dar es Salaam University

College of Education

University of Dar es Salaam

alusekelo@duce.ac.tz

\section{References}

Abdulaziz M.H. Mkilifi. 1972. Triglossia and Swahili-English bilingualism in Tanzania. Language in Society, 1(2): 197-213.

Århem, K. 1985. The Maasai and the state: The impact of rural development policies on a pastoral people in Tanzania. Copenhagen: IWGA document no 52.

Backhaus, Peter. 2007. Linguistic landscapes: A comparative study of urban multilingualism in Tokyo. Clevedon: Multilingual Matters Ltd.

Batibo, Herman M. 1992. The fate of ethnic languages in Tanzania. In Mattheas Brenzinger (ed.) Language death: Factual and theoretical explorations, with special reference to East Africa, 85-98. Berlin: Mouton de Gruyter.

. 2000. The linguistic situation in Tanzania. In Kulikoyela Kahigi,

Maarten Mous \& Yared Kihore (Eds.). Lugha za Tanzania, 517. Amsterdam: Mouton de Gruyter.

. 2005. Language decline and death in Africa: Causes, consequences and challenges. Clevedon: Multilingual Matters Ltd. 
Ben-Rafael, Eliezer, Elena Shohamy, Muhammad H. Amara \& Nira Trumper-Hecht. 2006. Linguistic landscape as symbolic construction of the public space: The case of Israel. In Linguistic landscape: A new approach to multilingualism, ed. Durk Goeter, pp. 7-30. Clevedon: Multilingual Matters Ltd.

Blommaert, Jan. 1992. Codeswitching and the exclusivity of social identities: Some data from campus Kiswahili. Journal of Multilingual and Multicultural Development, 13(1-2): 57-70. . 2013. State ideology and language in Tanzania, second revised edition. Tilburg Papers in Culture Studies. Tilburg University, Paper 80.

Blommaert, Jan \& Ico Maly. 2014. Ethnographic linguistic landscape analysis and social change: A case study. Tilburg Papers in Culture Studies, Paper 100, Tilburg University.

Bwenge, Charles. 2009. Language choice in Dar es Salaam's billboards. In Fiona McLaughlin (ed.). The languages of urban Africa, 152177. London: Continuum International Publishing Group.

_ 2012. English in Tanzania: A linguistic cultural perspective. International Journal of Language, Translation and Intercultural Communication, 1(1): 167-182.

Cenoz, Jasone \& Durk Gorter.2006. linguistic landscape and minority languages. In Linguistic landscape: A new approach to multilingualism, ed. Durk Goeter, pp. 67-82. Clevedon: Multilingual Matters Ltd.

Chul-joon, Yang. 2014. Shifting agency in shaping linguistic landscape: Evidence from Dar es Salaam, Tanzania. The Sociolinguistic Journal of Korea, 22 (2): 45-64.

Dowling, Tessa. 2010. 'Akuchanywa apha please' No peeing here please: The language of signage in Cape Town. South African Journal of African Languages, 30 (2): 192-208.

Dowling, Tessa. 2012. Translated for the dogs: Language use in Cape Town signage. Language Matters, 43 (2): 240-262.

Huebner, Thom. 2006. Bangkok's linguistic landscapes: Environmental print, codemixing and language change. In Linguistic landscape: 
A new approach to multilingualism, ed. Durk Goeter, pp. 31-51. Clevedon: Multilingual Matters Ltd

Hodgson, Dorothy L. 2005. The Church of Women: Gendered Encounters between Maasai and Missionaries. Bloomington: Indiana University Press.

. 2011. Being Maasai, becoming indigenous: Postcolonial politics in a neoliberal world. Bloomington: Indiana University Press.

Homewood, Katherine, Patti Kristjanson \& Pippa C. Trench. 2009. Staying Maasai?: Livelihood, conservation and development in East Africa, New York: Springer.

Jacobs, Alan H. 1978. Development in Tanzania Maasailand: The perspective over 20 years, 1957-1977. Dar es Salaam: The USAID Mission in Tanzania.

Higgins, Christina. 2009. English as a local language: Post-colonial identities and multilingual practices. Bristol: Multilingual Matters.

Keya, Antoni. 2016. "Nani aliamua?" Sera ya lugha na kitokeacho mahakamani Tanzania. Journal of Languages in Education and Linguistics, 10 (1): 20-36.

Kotze, Chrismi-Rinda and Theodorus du Plessis. 2010. Language visibility in the Xhariep: A comparison of the linguistic landscape of three neighbouring towns. Language Matters: Studies in the Languages of Africa, 41 (1): 72-96.

Lanza, Elizabeth \& Hirut Woldermariam. 2009. Language ideology and linguistic landscape: Language policy and globalisation in a regional capital of Ethiopia. In Linguistic landscape: Expanding the scenery, ed. Elena Shohamy \& Durk Gorter, pp. 189-205. New York: Routledge.

. 2014. Indexing modernity: English and branding in LL of Addis Ababa. International Journal of Bilingualism, 18(5): 23-49.

Legère, Karstens \& Tove Rosendal. 2019. Linguistic landscapes and the African perspective. In Expanding the Linguistic Landscape: Linguistic Diversity, Multimodality and the Use of Space as a 
Semiotic Resource, ed. M. Pütz and N. Mundt, pp. 153-179. Multilingual Matters.

LOT (Language of Tanzania Project). 2009. Atlasi ya lugha za Tanzania. Dar es Salaam: University of Dar es Salaam.

Lusekelo, Amani. 2015. The Hadzabe society of Tanzania: Contacts, sociolinguistics and onomastics. Ibadan: John Archers Publishers Limited.

Lusekelo, Amani and Chrispina Alphonce. 2018. "The Linguistic Landscape in Urban Tanzania: An Account of the Language of Billboards and Shop-signs in District Headquarters" Journal of Language, Technology and Entrepreneurship in Africa 9(1), 132.

McLaughlin, Fiona 2012. The languages of urban Africa. London: Continuum International Publishing Group.

Mdukula, Paschal C. 2018. Linguistic Landscape of Public Health Institutions in Tanzania: The Case of Muhimbili National Hospital. Doctoral thesis, University of Dar es Salaam.

Msanjila, Yohana P. 2003. Kushuka kwa hadhi ya lugha za jamii nchini Tanzania. Nordic Journal of African Studies, vol. 12(3): 296309.

. 2004. The future of the Kisafwa language: The case of the Ituha village in Tanzania. Journal of Asian and African Studies, vol. 68: 161-171.

Muzale, Henry R.T \& Josephat M. Rugemalira. 2008. Researching and documenting the languages of Tanzania. Language Documentation \& Conservation, 2(1): 68-108.

Myers-Scotton, Carol. 1993. 2006. Multiple voices: An introduction to bilingualism. Malden, MA: Blackwell.

Ndagala, Daniel K. 1982. 'Operation impartnati': The sedentarization of the pastoral Maasai in Tanzania. Nomadic Peoples, 10: 28-39.

Omri-Pack, Monika. 1998. Transformations in the Maasai economy and resource utilizations: Kisonko in Northern Tanzania. In Amelie Berger (Ed.). Twice humanity: Implications for local and global resource use, 87-100. Uppsala: The Nordic African Institute. 
Peck, Amiena \& Felix Banda. 2009. Observatory's linguistic landscape: Semiotic appropriation and the reinvention of space. Social Semiotics, 24(3): 302-323.

Peterson, Rhoda. 2014. Matumizi na dhima za lugha katika mandharilugha ya jiji la Dar es Salaam. Doctoral thesis, University of Dar es Salaam.

Petzell, Malin. 2012. The linguistic situation in Tanzania. Moderna Språk, 1: 136-144.

Quayson, Ato. 2010. Signs of the time: Discourse ecologies and street life on Oxford St., Accra. City \& Society, 22(1): 72-96.

Rosendal, Tove. 2010. Linguistic landscape: A comparison of official and non-official language management in Rwanda and Uganda, focusing on the position of African languages. Doctoral thesis, University of Gothenburg.

Roy-Campbell, Zaline M. \& Martha Qorro. 1997. The language crisis in Tanzania: The myth of English versus education. Dar es Salaam: Mkuki na Nyota Publishers.

Rubagumya Casmir M. 1991. Language promotion for education purposes: The example of Tanzania. International Review of Education, 37 (1): 67-85.

2003. English medium primary schools in Tanzania: A new "linguistic market" in education? In Brock-Utne, Birgit, Saline Zubeida \& Martha Qorro. (eds.). Language of Instruction in Tanzania and South Africa (LOITASA), 149-169. Dar es Salaam: E\&D Limited.

Sachedina, Hassan \& Pippa C. Trench. 2009. Cattle and crops, tourism and tanzanite: Poverty, land-use change and conservation in Simanjiro district, Tanzania. In Staying Maasai?: Livelihood, conservation and development in East Africa, ed. Katherine Homewood, Patti Kristjanson \& Pippa C. Trench, 263-298. New York: Springer.

Stroud, Christopher \& Sibonile Mpendukana. 2009. Towards a material ethnography of linguistic landscape: Multilingualism, mobility 
and space in South African township. Journal of Sociolinguistics, 13(3): 363-386.

URT (United Republic of Tanzania). 1988. Population census in Tanzania. Dar es Salaam: National Bureau of Statistics.

. 1997. Sera ya utamaduni. Dar es Salaam: Ministry of Education and Culture.

1998. Arusha region: Socio-economic profile. Dar es Salaam:

Minister of State Planning and Parastatal Sector Reform.

. 2002. Population and housing census: Population distribution by administrative areas. Dar es Salaam: National Bureau of Statistics.

. 2003. Sera ya Habari na Utangazaji. Dar es Salaam: Ministry of Information and Broadcasting.

. 2013. 2012 Population and housing census: Population distribution by administrative areas. Dar es Salaam: National Bureau of Statistics.

. 2015. Simanjiro constituency, wards and registration centres. Dar es Salaam: National Electoral Commission of Tanzania.

Yanda, Pius Z. \& Christopher William. 2010. Livelihoods diversifications and implications on food security and poverty levels in the Maasai plains: The case of Simanjiro district, Northern Tanzania. African Journal of Environmental Science and Technology, 4(3): 154-166. 